\title{
Adhesion of Electrospun Poly(acrylonitrile) Nanofibers on Conductive and Isolating Foil Substrates
}

\author{
Christian Hellert ${ }^{1}$, Martin Wortmann ${ }^{1}\left(\mathbb{D}\right.$, Natalie Frese ${ }^{2}$, Georg Grötsch ${ }^{3}$, Carsten Cornelißen ${ }^{3}$ and \\ Andrea Ehrmann 1,*(D) \\ 1 Faculty of Engineering and Mathematics, Bielefeld University of Applied Sciences, \\ Interaktion 1, 33619 Bielefeld, Germany; christian.hellert@fh-bielefeld.de (C.H.); \\ martin.wortmann@fh-bielefeld.de (M.W.) \\ 2 Faculty of Physics, Bielefeld University, Universitätsstraße 25, 33615 Bielefeld, Germany; \\ nfrese@uni-bielefeld.de \\ 3 InovisCoat GmbH, Rheinparkallee 3, 40789 Monheim am Rhein, Germany; \\ georg.groetsch@innoviscoat.de (G.G.); carsten.cornelissen@innoviscoat.de (C.C.) \\ * Correspondence: andrea.ehrmann@fh-bielefeld.de
}

check for updates

Citation: Hellert, C.; Wortmann, M.; Frese, N.; Grötsch, G.; Cornelißen, C.; Ehrmann, A. Adhesion of Electrospun Poly(acrylonitrile) Nanofibers on

Conductive and Isolating Foil Substrates. Coatings 2021, 11, 249. https: / / doi.org/10.3390/ coatings11020249

Academic Editors: Xinyu Zhang and Yeau-Ren Jeng

Received: 16 November 2020

Accepted: 17 February 2021

Published: 19 February 2021

Publisher's Note: MDPI stays neutral with regard to jurisdictional claims in published maps and institutional affiliations.

Copyright: (c) 2021 by the authors. Licensee MDPI, Basel, Switzerland. This article is an open access article distributed under the terms and conditions of the Creative Commons Attribution (CC BY) license (https:// creativecommons.org/licenses/by/ $4.0 /)$.

\begin{abstract}
Electrospinning can be used to prepare nanofibers from various polymers and polymer blends. The adhesion of nanofibers to the substrates on which they are electrospun varies greatly with the substrate material and structure. In some cases, good adhesion is desired to produce sandwich structures by electrospinning one material directly onto another. This is the case, e.g., with dye-sensitized solar cells (DSSCs). While both pure foil DSSCs and pure electrospun DSSCs have been examined, a combination of both technologies can be used to combine their advantages, e.g., the lateral strength of foils with the large surface-to-volume ratio of electrospun nanofibers. Here, we investigate the morphology and adhesion of electrospun nanofibers on different foil substrates containing materials commonly used in DSSCs, such as graphite, poly(3,4-ethylenedioxythiophene) polystyrene sulfonate (PEDOT:PSS) or $\mathrm{TiO}_{2}$. The results show that the foil material strongly influences the adhesion, while a plasma pretreatment of the foils showed no significant effect. Moreover, it is well known that conductive substrates can alter the morphology of nanofiber mats, both at microscopic and macroscopic levels. However, these effects could not be observed in the current study.
\end{abstract}

Keywords: electrospinning; polyacrylonitrile (PAN); nanofibers; conductive foils; adhesion; dyesensitized solar cells (DSSCs); fiber orientation

\section{Introduction}

Dye-sensitized solar cells (DSSCs) were first investigated in 1991 [1] and have been widely researched since then. To date, efficiencies above $20 \%$ can be achieved in laboratory environments [2].

The primary advantage of DSSCs is that they can be produced entirely from lowcost and non-toxic materials, even outside a cleanroom, making them feasible for nonspecialized companies, e.g., in the textile industry. However, high efficiencies on the same scale as silicon-based solar cells can only be achieved if similarly pure, high-quality-and usually highly toxic-materials are used. With less expensive and especially non-toxic materials, such as natural dyes, typical energy conversion efficiencies are on the order of a few percent or less [3-8]. It is well known that a reduction in cell area leads to a significant increase in efficiency $[9,10]$. However, for textile- or foil-based solar cells, it is advantageous to develop large-area DSSCs with sophisticated circuitry to increase the current.

Here we report the initial test results for combined textile- and foil-based DSSCs. In previous studies, we have shown that DSSCs can be purely electrospun [11], and have investigated the influence of different foil materials on DSSC properties [12]. The main objective of this study is to investigate the adhesion of nanofibers directly electrospun onto 
different substrates and the influence of the conductive substrate on fiber diameter and orientation [13-15]. The combination of conductive foils, which contain carbon materials in particular and can thus be used as counter electrodes, with insulating nanofiber mats is highly interesting, since the latter can be used to hold liquid electrolytes [11].

Sufficient mechanical adhesion is a prerequisite for good electrical contact between the various layers, which in turn is essential for high currents. A DSSC is composed of diverse layers with different functionalities. The outer layers are electrodes, one of which must be transparent to allow photons to enter the cell. A semiconducting layer is deposited on this front electrode, in many cases $\mathrm{TiO}_{2}$ or $\mathrm{ZnO}$. This semiconductor is dyed, e.g., with natural dyes containing anthocyanins. This dye can absorb a photon, exciting an electron, which is then injected into the semiconductor and directed to the front electrode. From there, it enters an external circuit with a load before being injected back into the solar cell at the counter electrode, which is supported by graphite or another catalyst. It then enters the electrolyte in the gap between the catalyst and the dyed semiconductor, where it recombines with an electrolyte acceptor before the latter reduces a dye cation to its neutral ground state, completing the circuit [16]. This brief sketch of the DSSC function underlines the importance of good contact between the adjacent layers. This study is therefore of general interest with respect to the design of new nanofiber/foil sandwich structures made of different materials.

A common method for improving adhesion between a substrate and a coating is the use of a plasma treatment to increase the polar component of the surface free energy, thereby decreasing the contact angle and facilitating adhesion [17-19]. Here, we investigated the influence of atmospheric pressure plasma treatment on the adhesion of nanofibers to the foil substrate.

\section{Materials and Methods}

The foils used for the experiments contained the following materials of interest for different layers of DSSCs: silver-copper $(\mathrm{Ag}-\mathrm{Cu})$ flakes with graphite; graphite with poly(3,4-ethylenedioxythiophene) polystyrene sulfonate (PEDOT:PSS); carbon black with PEDOT:PSS; PEDOT:PSS; $\mathrm{TiO}_{2}$ (titanium dioxide) with indium tin oxide (ITO); and $\mathrm{TiO}_{2}$ in a pure poly(ethylene terephthalate) (PET) foil. The latter is the only non-conductive one, added as a reference to study the influence of the conductivity.

Electrospinning was performed with a wire-based machine "Nanospider Lab" (Elmarco Ltd., Liberec, Czech Republic) using the following parameters: high voltage $65 \mathrm{kV}$, carriage speed $100 \mathrm{~mm} / \mathrm{s}$, nozzle diameter $1.5 \mathrm{~mm}$, distance between the bottom electrode and the substrate $240 \mathrm{~mm}$, distance between the ground electrode and the substrate $50 \mathrm{~mm}$, chamber temperature $22{ }^{\circ} \mathrm{C}$, and relative chamber humidity $32 \%$. Spinning was performed for $30 \mathrm{~min}$.

The spinning solution was prepared from $16 \mathrm{wt} . \%$ polyacrylonitrile (PAN) (copolymer with $6 \%$ methyl methacrylate, Dralon, Dormagen, Germany) dissolved in DMSO (min. $99.9 \%$, S3 Chemicals, Bad Oeynhausen, Germany) by stirring at room temperature for $2 \mathrm{~h}$.

The foils were cut into $5 \mathrm{~cm} \times 5 \mathrm{~cm}$ areas and glued onto a non-conductive polypropylene substrate placed in the Nanospider Lab prior to electrospinning.

The atmospheric pressure plasma system used for the pretreatment of some of the samples uses a rotating arc to generate a compressed air stream of ionized particles that is accelerated through a nozzle toward the sample surface to introduce oxygenated chemical bonds. An FG 5001 plasma generator, a PFW10 plasma nozzle and an RD1004 nozzle attachment from Plasmatreat (Steinhagen, Germany) were used for the plasma treatment. The distance of the plasma nozzle to the surface was $20 \mathrm{~mm}$ and the treatment speed was $50 \mathrm{~mm} / \mathrm{s}$. Compressed air with a constant volumetric flow rate of $35 \mathrm{~L} / \mathrm{min}$ was used as process gas. The plasma-specific parameters were the following: generator voltage $280 \mathrm{~V}$, frequency $23 \mathrm{kHz}$, plasma cycle time $100 \%$.

The adhesion of the nanofiber mats to the foils was measured with a dynamic mechanical analysis (DMA) "DMA Q800" (TA Instruments, New Castle (DE), USA) according to 
DIN 53530. For this purpose, both materials were detached at one end of a cut test strip and fixed in the clamps of the DMA. The applied force at constant speed was measured for 6 specimens per substrate.

Nanofiber morphology studies were performed using a helium ion microscope (HIM) Orion Plus (Carl Zeiss, Jena, Germany), applying an acceleration voltage of $34 \mathrm{kV}$ and a corresponding beam current of 1.4-1.6 pA. Charging effects during secondary electron detection were avoided by sputtering a $10 \mathrm{~nm}$ platinum coating onto the nanofiber mats.

Fiber diameters and orientations were evaluated using ImageJ 1.51j8 (National Institutes of Health, Bethesda, MD, USA). Angular distributions were investigated by fast Fourier transform (FFT). The FFT images show single lines for the aligned fibers and radial diffusion patterns for the arbitrarily oriented fibers $[15,20]$. The ImageJ plugin OrientationJ [21] was used for color-coding the fibers according to their angular orientation, as well as for the analysis of the distribution of angular fiber orientation. It should be mentioned that the tests showed that this plugin can only be reliably used for images with fiber widths of several pixels; if the fibers are displayed with only very few pixels per diameter, artifacts will occur, apparently favoring $0^{\circ}, \pm 45^{\circ}$ and $\pm 90^{\circ}$. The evaluations are therefore only shown for the more highly magnified HIM images.

\section{Results and Discussion}

Figure 1 shows the adhesion forces between the nanofibers electrospun onto different foil substrates. The force is generally rather low, but in technical applications this can be compensated for through the mechanical protection of the layers, such as by soldering the edges to withstand frictional forces that would otherwise separate the layers.

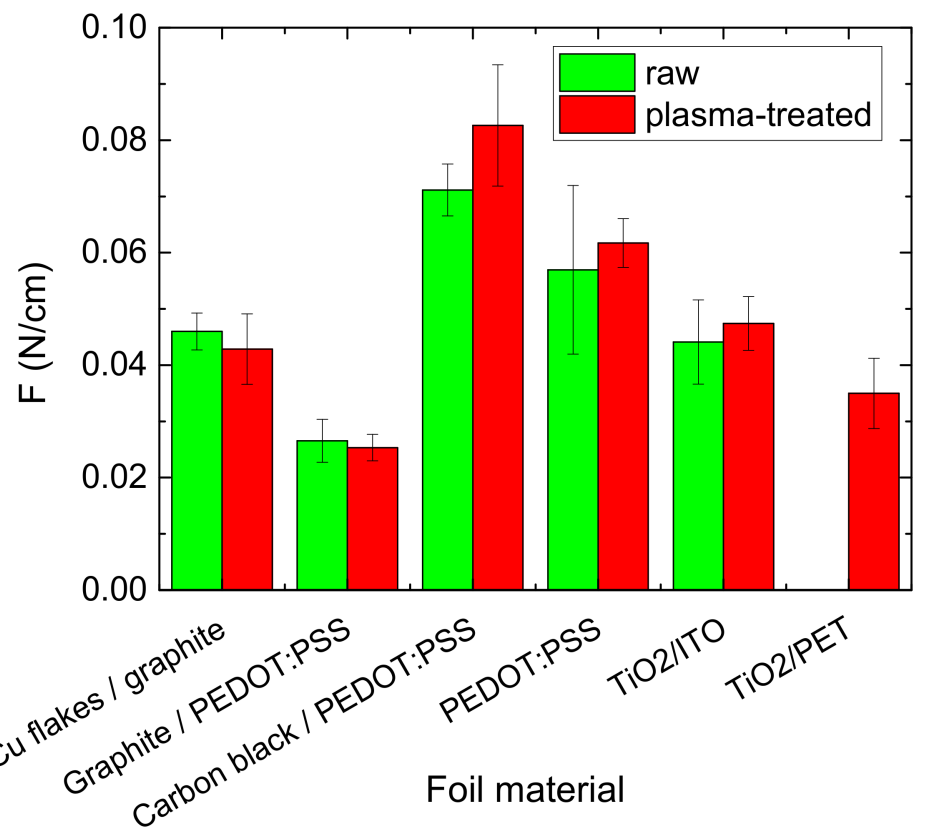

Figure 1. Adhesion forces of nanofibers electrospun onto foil substrates, with and without a preceding plasma treatment of the foils.

Unexpectedly, in most cases, the preceding plasma treatment does not significantly increase the adhesion. Although some samples have shown a slight increase, the effect is marginal, as indicated by the overlapping error bars. Since it is known that the effect of plasma treatment decreases over time due to the adsorbing of substances from the atmosphere or the self-diffusion of the treated material, all of the samples were electrospun within a maximum of $3 \mathrm{~h}$ after the treatment. Since values in the literature of the relaxation times of the surface modifications by plasma treatments are reported from approx. 1 day to 6 weeks, depending on the plasma treatment parameters [22-25], this duration can be 
expected to be short enough to avoid the relaxation of the effect. Shorter time spans were not possible due to the different locations of the plasma and electrospinning equipment; longer time spans were not tested since the minimum possible time already showed no significant effect. Only in the case of $\mathrm{TiO}_{2} / \mathrm{PET}$ could adhesion be achieved at all by plasma treatment. However, this foil was only added as a non-conductive reference, and is thus not of interest for the application in DSSCs. This suggests that for the conductive foils used in DSSCs, a plasma treatment is not advantageous.

When comparing the different foils, on the other hand, significant differences can be found. The adhesion is lowest on the graphite/PEDOT:PSS foils, which were already used in a previous study to prepare foil-based DSSCs [12]. In contrast, the similar carbon black/PEDOT:PSS showed more than twice the adhesive force, making it a promising candidate for future DSSC applications.

As shown in Figure 2, the effect of some foil substrates was investigated using an HIM. All of the conductive foils have similar in-plane resistivity ( $\mathrm{Ag}-\mathrm{Cu}$ flakes/graphite: $\sim 180 \Omega$ /cm; carbon black/PEDOT:PSS: $\sim 200 \Omega / \mathrm{cm}$; $\mathrm{TiO}_{2} /$ ITO: $\sim 120 \Omega / \mathrm{cm}$ ), while the originally non-conductive $\mathrm{TiO}_{2} / \mathrm{PET}$ foil has a weakly conductive coating on the back to avoid electrostatic charging, resulting in $\sim 30 \mathrm{M} \Omega / \mathrm{cm}$.

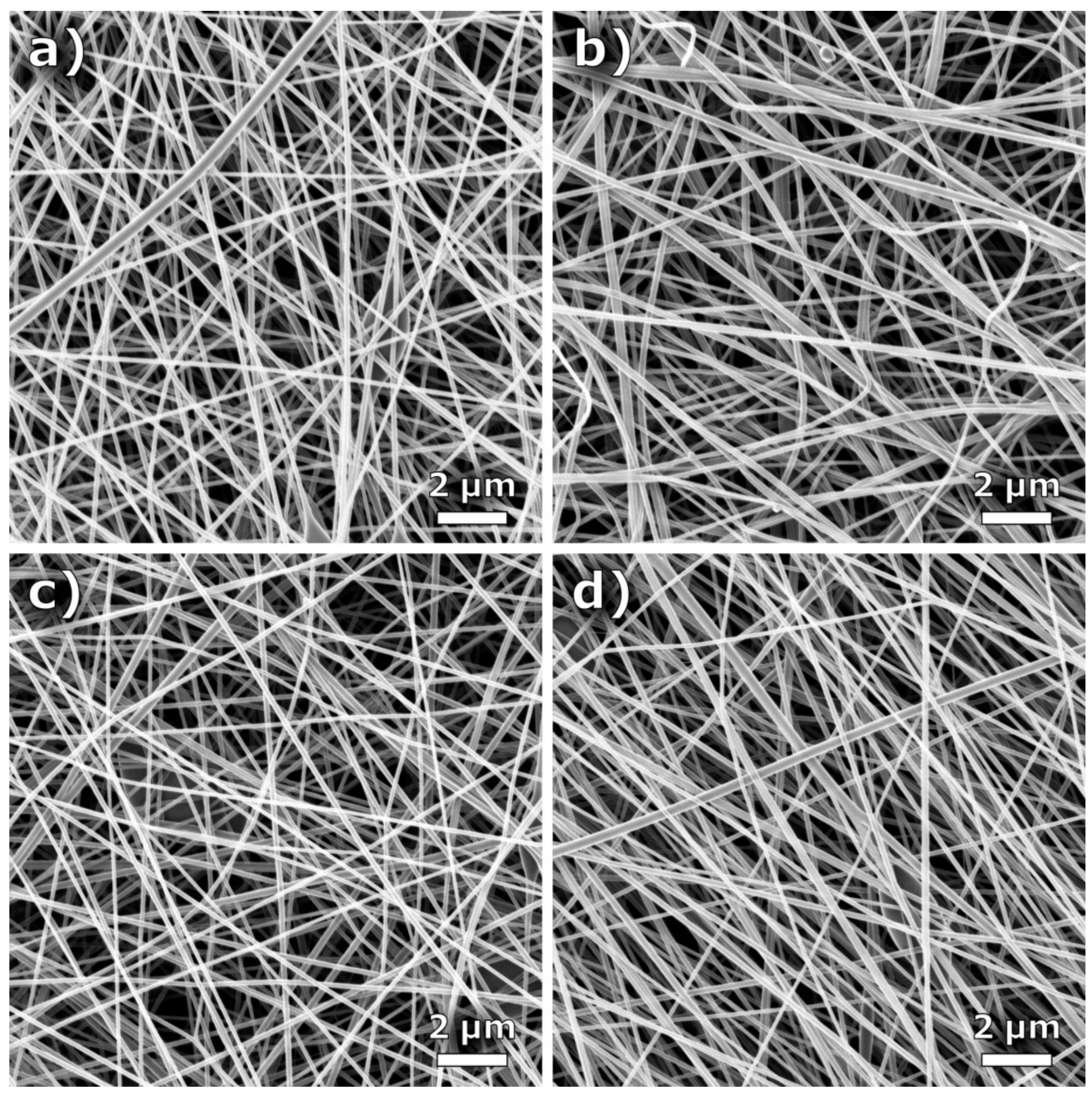

Figure 2. Helium ion microscope (HIM) images of the nanofibers on (a) silver-copper ( $\mathrm{Ag}-\mathrm{Cu})$ flakes/graphite, (b) carbon black/poly(3,4-ethylenedioxythiophene) polystyrene sulfonate (PEDOT:PSS), (c) $\mathrm{TiO}_{2} / \mathrm{ITO}$ and (d) $\mathrm{TiO}_{2} /$ PET.

In contrast to previous investigations $[15,26]$, no significant differences between the nanofibers electrospun onto the conductive (Figure $2 \mathrm{a}-\mathrm{c}$ ) and the non-conductive foils 
(Figure 2d) could be observed. The diameters and diameter distributions appear very similar; a certain fiber orientation - which would be expected for partly conductive areas with a high aspect ratio [15] — is rather visible on the non-conductive substrate. It is worth mentioning that on partially conductive substrates, higher nanofiber deposition is typically expected on conductive regions. The reason for this is the local deformation of the electric field between the two wires of the spinning device [15,27-33]. Therefore, it is rather unexpected that no differences could be observed between the nanofibers deposited on the conductive films and the insulating ones.

To avoid a possible bias due to the choice of the image section [34], Figure 3 shows HIM images of the same samples with a larger field of view. Here, again, almost no differences are visible.
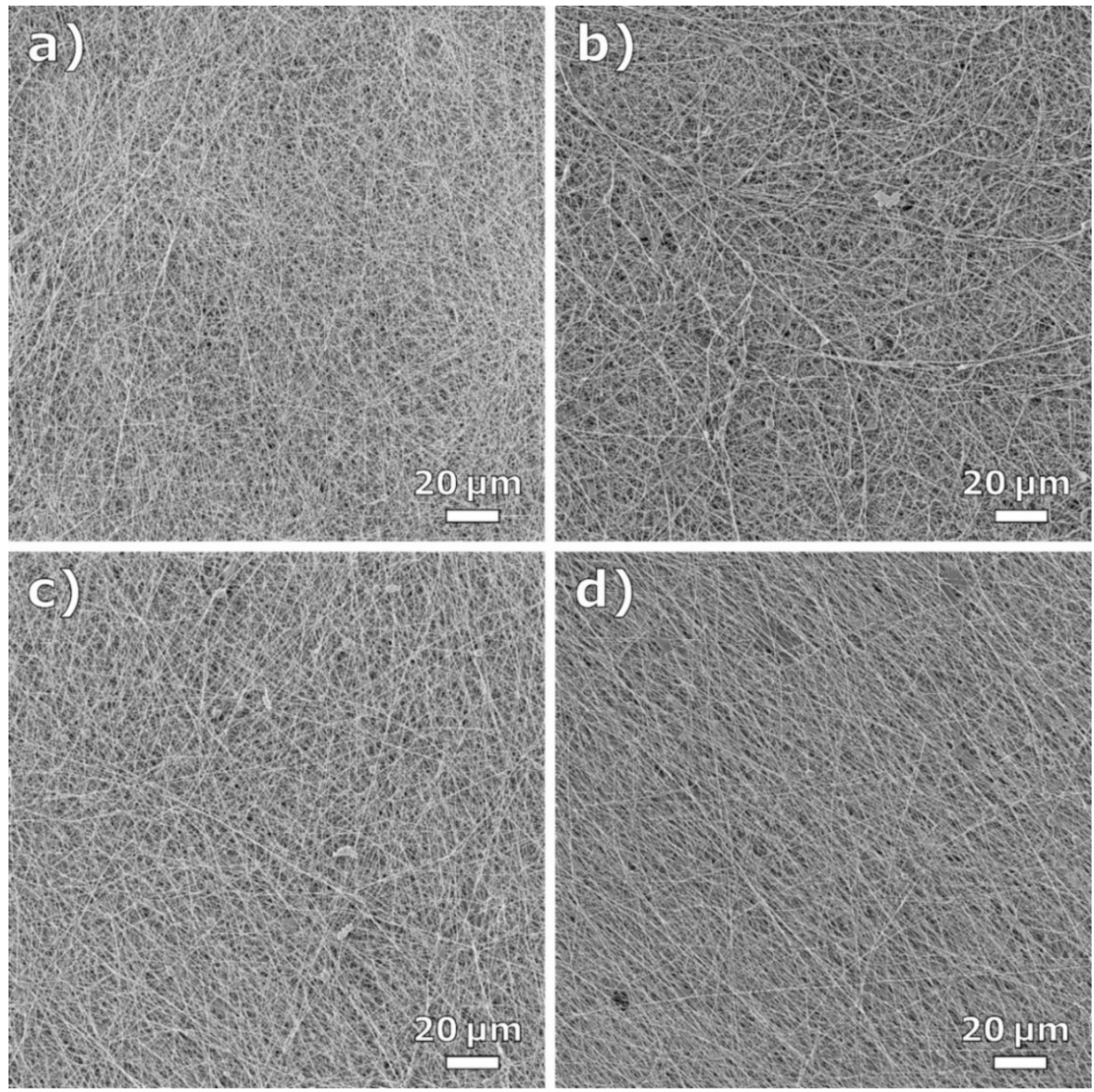

Figure 3. HIM images with larger fields of view of the nanofibers on (a) Ag-Cu flakes/graphite, (b) carbon black/PEDOT:PSS, (c) $\mathrm{TiO}_{2} / \mathrm{ITO}$ and (d) $\mathrm{TiO}_{2} /$ PET.

Figure 4 depicts histograms of the nanofiber diameters, as measured from the HIM images in Figure 2, underlining that the mean values and standard deviations are indeed nearly identical for all the nanofiber mats. Apparently, the substrate has therefore no discernible influence on the fiber diameter. 

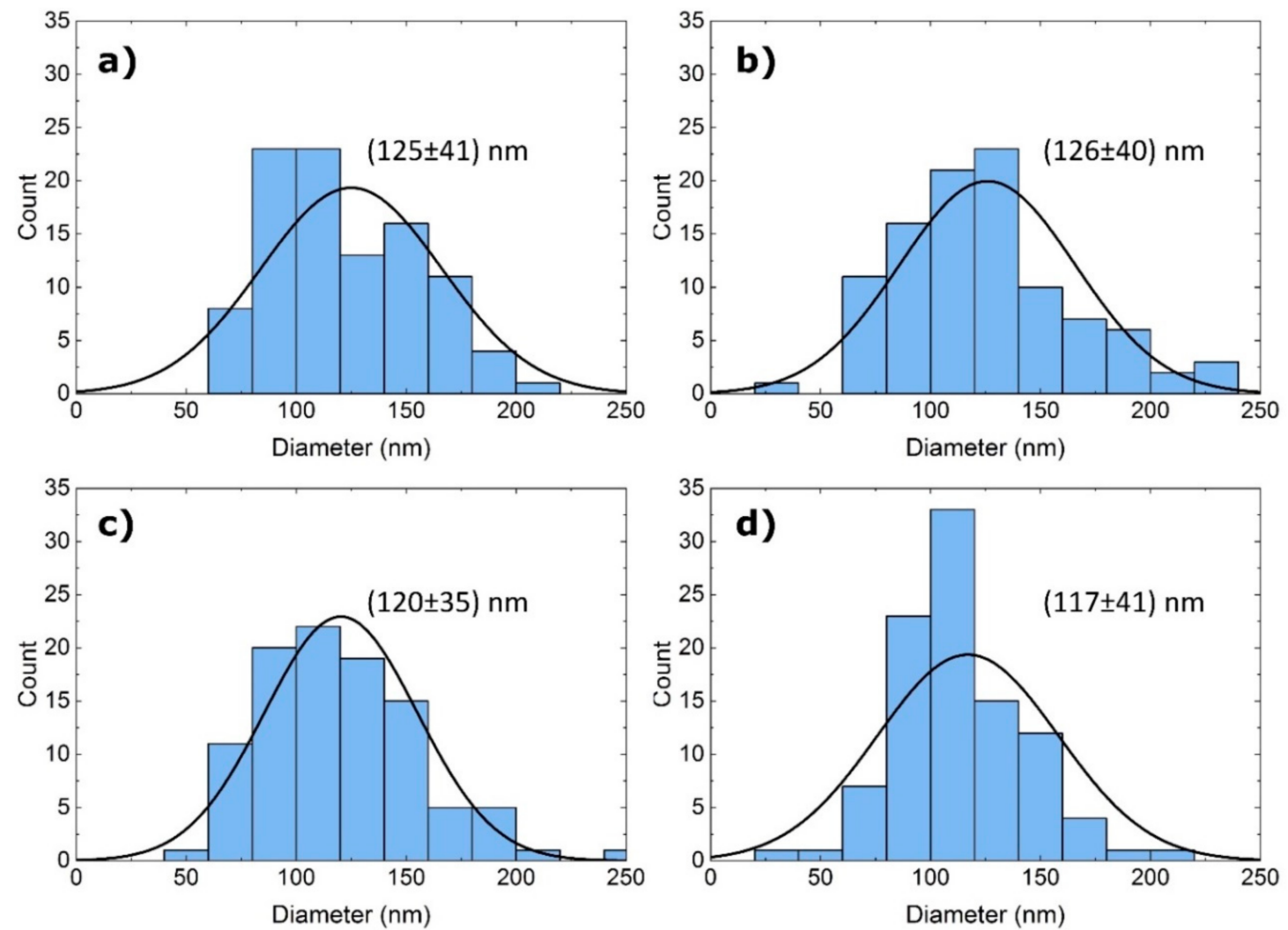

Figure 4. Diameter distributions of the nanofibers on (a) Ag-Cu flakes/graphite, (b) carbon black/PEDOT:PSS, (c) TiO $2 /$ ITO and (d) $\mathrm{TiO}_{2} /$ PET.

On the other hand, partially conductive substrate areas can influence the orientation of electrospun nanofibers [13-15]. Figure 5 depicts the FFT analysis of the HIM images shown in Figure 2, as well as the HIM images color-coded according to the fiber orientations. The corresponding angular distributions are depicted in Figure 5e. The color-coded images and the FFT graphs seem to show a slightly stronger fiber orientation for $\mathrm{TiO}_{2} / \mathrm{PET}$ (Figure $5 \mathrm{~d}$ ), which is supported by the quantitative analysis in Figure 5e, showing a higher peak in the normalized fiber distribution (blue line). The influence of large conductive regions in the spinning area on the electric field is apparently negligible.
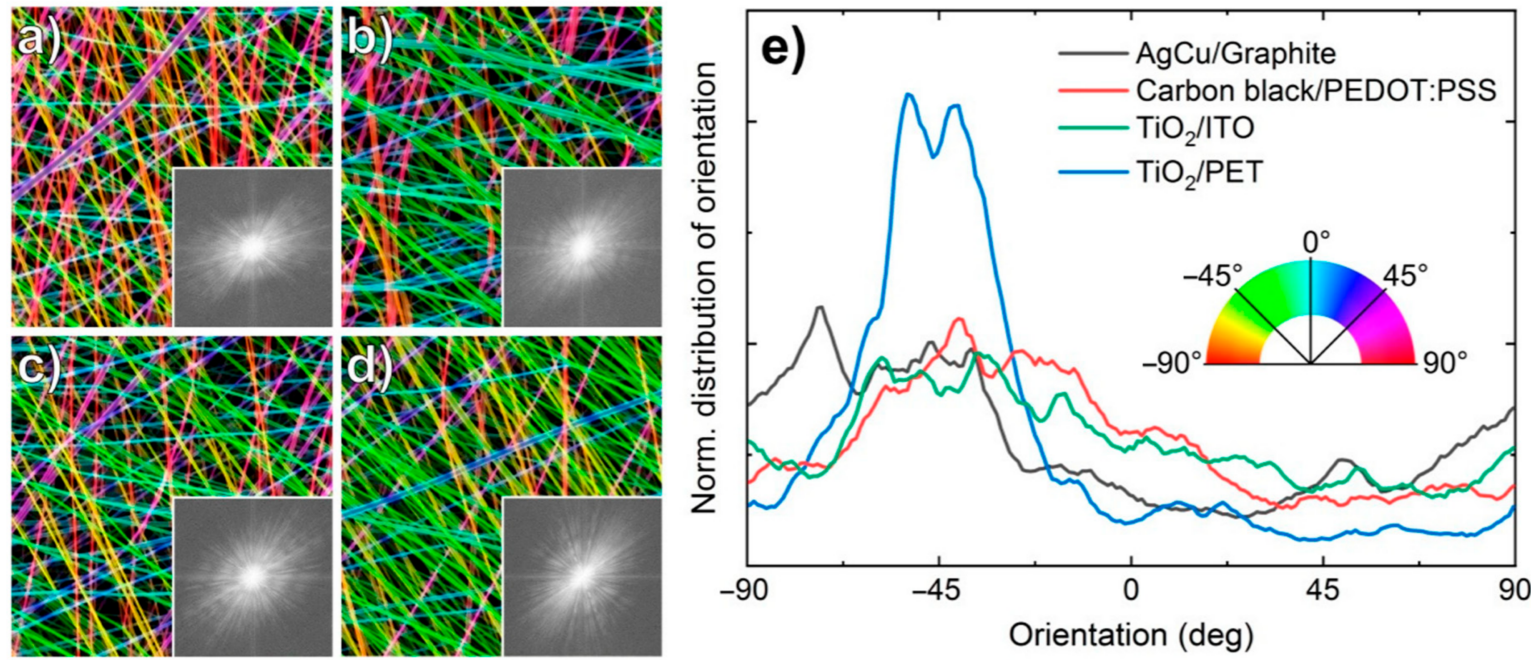

Figure 5. HIM images of the nanofibers color-coded according to their orientations on (a) Ag-Cu flakes/graphite, (b) carbon black/PEDOT:PSS, (c) $\mathrm{TiO}_{2} / \mathrm{ITO}$ and (d) $\mathrm{TiO}_{2} /$ PET. Insets show FFT spectra of the respective HIM images; (e) angular distributions of the fibers calculated by OrientationJ. 
It should be mentioned that the most important results from this study are so-called "negative results", casting doubt on common assumptions. Here, the presumption that plasma treatments increase the adhesion of coatings, in this case the direct deposition of nanofibers on polymer foils, could not be substantiated. Often "negative results" remain unpublished, which leads to the unnecessary repetition of experiments and a waste of resources. The significance of the so-called publication bias has often been addressed in critical papers from a wide range of scientific fields [35-39]. The fact that plasma treatments do not increase the adhesion of nanofibers electrospun onto polymer foils raises the question of how the adhesion of electrospun nanofibers on polymeric substrates can be described theoretically, which parameters are decisive, and how the adhesion can be either reduced or increased, depending on the desired application.

\section{Conclusions}

In this study, the feasibility of hybrid textile-foil DSSCs was demonstrated by directly electrospinning nanofibers onto different foil substrates. The conductivity of the foils modified neither the nanofiber diameters nor their orientations; oppositely, a certain fiber orientation became visible only on the non-conductive substrate. On the other hand, the different foil materials significantly influenced the adhesion between both layers, which is an important parameter for reaching sufficient contact for applications in electrical devices. In most cases, a pre-treatment of the foils by atmospheric pressure plasma did not significantly increase the adhesion between the nanofibers and the substrate.

To better understand this behavior, it is planned to investigate the deposition of the very first fibers onto the substrates in the near future. This can also help to model and tailor the adhesion of electrospun nanofibers onto polymeric or other substrates.

Author Contributions: Conceptualization, C.H. and A.E.; formal analysis, M.W. and A.E.; investigation, C.H.; M.W.; N.F.; C.C.; writing-original draft preparation, M.W. and A.E.; writing-review and editing, all authors; visualization, M.W.; supervision, G.G. All authors have read and agreed to the published version of the manuscript.

Funding: This project was partly funded by Deutsche Bundesstiftung Umwelt DBU (German Federal Environmental Foundation).

Institutional Review Board Statement: Not applicable.

Informed Consent Statement: Not applicable.

Data Availability Statement: All data gained during the study are shown in this paper.

Acknowledgments: We are grateful to Armin Gölzhäuser from Bielefeld University for providing the opportunity to use the helium ion microscope. We would also like to thank Moritzer from the Kunststofftechnik Paderborn at the Paderborn University for providing the plasma system.

Conflicts of Interest: The authors declare no conflict of interest.

\section{References}

1. O'Reagan, B.; Grätzel, M. A low cost, high efficiency solar cell based on dye sensitized colloidal TiO 2 films. Nature 1991, 353, 737-740. [CrossRef]

2. Freitag, M.; Teuscher, J.; Saygili, Y.; Zhang, X.; Giordano, F.; Liska, P.; Hua, J.; Zakeeruddin, S.M.; Moser, J.-E.; Grätzel, M.; et al. Dye-sensitized solar cells for efficient power generation under ambient lighting. Nat. Photonics 2017, 11, 372. [CrossRef]

3. Juhász Junger, I.; Homburg, S.V.; Meissner, H.; Grethe, T.; Schwarz-Pfeiffer, A.; Fiedler, J.; Herrmann, A.; Blachowicz, T.; Ehrmann, A. Influence of the $\mathrm{pH}$ value of anthocyanins on the electrical properties of dye-sensitized solar cells. AIMS Energy 2017, 5, 258-267. [CrossRef]

4. Sinha, D.; De, D.; Ayaz, A. Performance and stability analysis of curcumin dye as a photo sensitizer used in nanostructures ZnO based DSSC. Spectrochim. Acta A Mol. Biomol. Spectrosc. 2018, 193, 467-474. [CrossRef] [PubMed]

5. Hölscher, F.; Trümper, P.-R.; Juhász Junger, I.; Schwenzfeier-Hellkamp, E.; Ehrmann, A. Raising reproducibility in dye-sensitized solar cells under laboratory conditions. J. Renew. Sustain. Energy 2018, 10, 013506. [CrossRef]

6. Lucioli, S.; Di Bari, C.; Forni, C.; Di Carlo, A.; Barrajón-Catalán, E.; Micol, V.; Nota, P.; Teoli, F.; Matteocci, F.; Frattarelli, A.; et al. Anthocyanic pigments from elicited in vitro grown shoot cultures of Vaccinium corymbosum L., cv. Brigitta Blue, as photosensitizer in natural dye-sensitized solar cells (NDSSC). J. Photochem. Photobiol. B Biol. 2018, 188, 69-76. [CrossRef] 
7. Sanjay, P.; Deepa, K.; Madhavan, J.; Senthil, S. Optical, spectral and photovoltaic characterization of natural dyes extracted from leaves of Peltophorum pterocarpum and Acalypha amentacea used as sensitizers for ZnO based dye sensitized solar cells. Opt. Mater. 2018, 83, 192-199. [CrossRef]

8. Ehrmann, A.; Blachowicz, T. Comment on 'Dye-sensitized solar cells using Aloe Vera and Cladode of Cactus extracts as natural sensitizers' [Chem. Phys. Lett. 679 (2017) 97-101]. Chem. Phys. Lett. 2019, 714, 227-229. [CrossRef]

9. Udomrungkhajornchai, S.; Juhász Junger, I.; Ehrmann, A. Optimization of the $\mathrm{TiO}_{2}$ layer in DSSCs by a nonionic surfactant. Opt. Int. J. Light Electron. Opt. 2020, 203, 163945. [CrossRef]

10. Juhász Junger, I.; Udomrungkhajornchai, S.; Grimmelsmann, N.; Blachowicz, T.; Ehrmann, A. Effect of Caffeine Copigmentation of Anthocyanin Dyes on DSSC Efficiency. Materials 2019, 12, 2692. [CrossRef] [PubMed]

11. Kohn, S.; Wehlage, D.; Juhász Junger, I.; Ehrmann, A. Electrospinning a dye-sensitized solar cell. Catalysts 2019, 9, 975. [CrossRef]

12. Kohn, S.; Großerhode, C.; Storck, J.L.; Grötsch, G.; Cornelißen, C.; Streitenberger, A.; Grassmann, C.; Schwarz-Pfeiffer, A.; Ehrmann, A. Commercially available teas as possible dyes for dye-sensitized solar cells. Opt. Int. J. Light Electron. Opt. 2019, 185, 178-182. [CrossRef]

13. Feng, J.P.; Wang, J.; Hwang, W.T.; Jo, Y.M. Characterization of filter media prepared from aligned nanofibers for fine dust screen. J. Appl. Polym. Sci. 2019, 136, 48166. [CrossRef]

14. Kim, D.; Eom, S.; Park, S.M.; Hong, H.; Kim, D.S. A collagen gel-coated, aligned nanofiber membrane for enhanced endothelial barrier function. Sci. Rep. 2019, 9, 14915. [CrossRef] [PubMed]

15. Storck, J.L.; Grothe, T.; Mamun, A.; Sabantina, L.; Klöcker, M.; Blachowicz, T.; Ehrmann, A. Orientation of electrospun magnetic nanofibers near conductive areas. Materials 2020, 13, 47. [CrossRef] [PubMed]

16. Ye, M.; Wen, X.; Wang, M.; Iocozzia, J.; Zhang, N.; Lin, C.J.; Lin, Z. Recent advances in dye-sensitized solar cells: From photoanodes, sensitizers and electrolytes to counter electrodes. Mater. Today 2015, 18, 155-162. [CrossRef]

17. Kim, J.; Mauchauffe, R.; Kim, D.; Kim, J.; Moon, S.Y. Mechanism study of atmospheric-pressure plasma treatment of carbon fiber reinforced polymers for adhesion improvement. Surf. Coat. Technol. 2020, 393, 125841. [CrossRef]

18. Bilek, M.M.M.; Vandrovcova, M.; Shelemin, A.; Kuzminova, A.; Kylian, O.; Biederman, H.; Bacakova, L.; Weiss, A.S. Plasma treatment in air at atmospheric pressure that enables reagent-free covalent immobilization of biomolecules on polytetrafluoroethylene (PTFE). Appl. Surf. Sci. 2020, 518, 146128. [CrossRef]

19. Ono, R.; Murakami, S. Quantitative measurement of the effect of OH radicals on the surface treatment of polypropylene. Plasma Process. Polym. 2020, 17, e2000024. [CrossRef]

20. Bazrafshan, Z.; Stylios, G.K. Custom-built electrostatics and supplementary bonding in the design of reinforced Collagen-g-P (methyl methacrylate-co-ethyl acrylate)/nylon 66 core-shell fibers. J. Mech. Behav. Biomed. Mater. 2018, 87, 19-29. [CrossRef]

21. Sage, D. OrientationJ-A Series of ImageJ Plugins for Directional Image Analysis. Available online: http://bigwww.epfl.ch/ demo/orientation/ (accessed on 28 January 2021).

22. Papakonstantinou, D.; Amanatides, E.; Mataras, D.; Ioannidis, V.; Nikolopoulos, P. Improved surface energy analysis for plasma treated PET films. Plasma Process. Polym. 2007, 4, S1057-S1062. [CrossRef]

23. Kotál, V.; Svorcik, V.; Slepicka, P.; Sajdl, P.; Bláhová, O.; Sutta, P.; Hnatowicz, V. Gold coating of poly(ethylene terephthalate) modified by argon plasma. Plasma Process. Polym. 2007, 4, 69-76. [CrossRef]

24. Prosycevas, I.; Guobiene, A.; Andrulevicius, M. Polyethylene terephthalate film surface relaxation after plasma treatment. Mater. Sci. Medziagotyra 2003, 9, 355-357.

25. Gupta, B.; Hilborn, J.; Hollenstein, C.; Plummer, C.J.G.; Houriet, R.; Xanthopoulos, N. Surface modification of polyester films by RF plasma. J. Appl. Polym. Sci. 2000, 78, 1083-1091. [CrossRef]

26. Hellert, C.; Storck, J.L.; Grothe, T.; Kaltschmidt, B.; Hütten, A.; Ehrmann, A. Positioning and aligning electrospun PAN fibers by conductive and dielectric substrate patterns. Macromol. Symp. 2021, 395, 2000213. [CrossRef]

27. Yao, Y.T.; Lu, H.B.; Leng, J.S.; Li, J.J. One-step Fabrication of Multifunctional Silica Microbelt with the Novel Stacked Structure by Electrospinning Technique. Proc. SPIE 2014, 9058, 905819.

28. Liu, S.L.; Sun, G.H.; Huang, Y.Y.; Sun, B.; Zhang, H.D.; Long, Y.Z. Fabrication and formation mechanism of electrospun spatially defined fibrous patterning structures on conductive and insulating substrates. Micro-Nano Technol. XV Key Eng. Mater. 2014, 609-610, 842-848. [CrossRef]

29. Hwang, K.Y.; Yu, W.R. Measuring tensile strength of nanofibers using conductive substrates and dynamic mechanical analyzer. Fibers Polym. 2009, 10, 703-708. [CrossRef]

30. Munir, M.M.; Widiyandari, H.; Iskandar, F.; Okuyama, K. Patterned indium tin oxide nanofiber films and their electrical and optical performance. Nanotechnology 2008, 19, 375601. [CrossRef] [PubMed]

31. Lee, S.-J.; Cho, N.-I.; Lee, D.Y. Effect of collector grounding on directionality of electrospun titania fibers. J. Eur. Ceram. Soc. 2007, 27, 13-15. [CrossRef]

32. Li, D.; McCann, J.T.; Xia, Y.N. Uniaxial alignment of electrospun nanofibers. Polym. Nanofibers ACS Symp. Ser. 2006, 918, 319-329.

33. Li, D.; Wang, Y.L.; Xia, Y.N. Electrospinning of polymeric and ceramic nanofibers as uniaxially aligned arrays. Nano Lett. 2003, 3, 1167-1171. [CrossRef]

34. Wortmann, M.; Layland, A.S.; Frese, N.; Kahmann, U.; Grothe, T.; Storck, J.L.; Blachowicz, T.; Grzybowski, J.; Hüsgen, B.; Ehrmann, A. On the reliability of highly magnified micrographs for structural analysis in materials science. Sci. Rep. 2020, 10, 14708. [CrossRef] 
35. Weintraub, P.G. The importance of publishing negative results. J. Insect Sci. 2016, 16, 1-2. [CrossRef] [PubMed]

36. Buvat, I.; Orlhac, F. The dark side of radiomics: On the paramount importance of publishing negative results. J. Nucl. Med. 2019, 60, 1543-1544. [CrossRef] [PubMed]

37. Kratochwill, T.R.; Levin, J.R.; Horner, R.H. Negative results: Conceptual and methodological dimensions in single-case intervention research. Remedial Spec. Educ. 2017, 39, 67-76. [CrossRef]

38. Nlinaric, A.; Horvat, M.; Smolcic, V.S. Dealing with the positive publication bias: Why you should really publish your negative results. Biochem. Med. 2017, 27, 030201.

39. Levin, L. Publishing negative results-Sometimes it is more important! Quintessence Int. 2014, 45, 635. 